Mineral physics from Japan

\section{Raymond Jeanloz}

Materials Science of the Earth's Interior. Edited by Ichiro Sunagawa.

Terra Scientific, Tokyo/Reidel: 1984.

Pp.653. Dfl. 340, \$120, £80.

How much good science can be purchased for $8 \times 10^{8}$ yen (approximately $\$ 4$ million at current rates)? Judging from this book, the answer is a lot.

Much of the leading research in mineral physics is being done in Japan, the work involving application of tools and principles from physics, chemistry, geology and materials science to the complex materials that make up our planet. Materials Science of the Earth's Interior summarizes research in mineral physics that was carried out during a three-year programme funded (with the amount mentioned) by the Japanese Ministry of Education. The programme was completed in 1981, and the book written in 1982, yet this volume is a remarkably up-to-date summary of work on the subject.

Although it emphasizes experiments over theoretical investigations, the book manages to cover a broad range of topics. For example, X-ray diffraction studies of silicate crystals and melts at temperatures up to $\sim 2,000^{\circ} \mathrm{C}$ are complemented by accounts of molecular dynamics calculations on molten silicates. Descriptions of techniques available for growing highquality crystals, including diamond and other high-pressure phases, are followed by a number of studies on defects, rheology, diffusion and natural occurrences of the same minerals. High-pressure research is well represented, particularly in the areas in which the Japanese have excelled: the development and application of large-volume presses, in situ studies of phase transformations and determinations of complex phase equilibria. Also notable are individual contributions summarizing recent work on the theory of transitionmetal compounds (Sugano and Ohnishi), the noble-gas geochemistry of natural diamonds (Ozima and co-workers), and the use of shock waves in high-pressure experiments (Syono and Goto). Overall, the articles bring together a great deal of material that was hitherto widely scattered or unavailable elsewhere in the literature.

The book will be especially interesting to the earth scientist who wants to know about advanced techniques that are now available and will become increasingly important in the study of geological materials. For the materials scientist or condensed-matter physicist, however, few clues are provided regarding the geological motivation for carrying out these studies; the connection between material properties and the evolution of planetary interiors is not explicitly examined. Still, the properties of complex inorganic systems such as minerals are of broad interest, and this book has allowed some of the leaders in mineral physics to describe frontier research in their field.

Raymond Jeanloz is in the Department of Geology and Geophysics, University of California, Berkeley.

\section{Beavering away}

\section{W.C. McGrew}

\section{Animal Architecture and Building}

Behaviour.

By Michael H. Hansell.

Longman: 1984. Pp.324. £25, $\$ 60$.

TWENTY-THREE families of birds, from bulbuls to wrens, gather and use spider silk in constructing their nests. Beetles living in the Namib desert dig shallow trenches in the sand to trap dew for drinking water. Mole-rats burrow as a team, from the excavator in front, through the "conveyor belt" of intermediates, to the soil-expeller at the end of the queue. These are some of the splendid examples of animals building, as recounted by Michael Hansell. His book would be welcome if it were just an encyclopaedia of such habits, but it is much more.

A fifth of the text is taken up with a survey of animal architecture, across the minor builders from protozoa to chimpanzees, but focusing on the three main classes of major builders: spiders, insects and birds. The rest is devoted to analysis of architecture as action. As an ethologist, the author considers the structure to be inseparable from the behaviour which creates it. $\mathrm{He}$ is a great lister: artefacts may serve four functions, namely, protection from the elements, defence against other organisms, aids to subsistence, and communication and display. (A beaver's dam may perform all four.) There are seven methods of construction - sculpting, piling-up, moulding, rolling and folding, stickingtogether, weaving, and sewing - birds, apparently, having the widest range. With such classificatory schemes, the author makes neat sense of a diverse array of knowledge, so that unexpected generalizations emerge; for example, the same properties of mud are exploited by organisms from termites to house martins.

For the scientist, animal artefacts have many uses. As products of behaviour they can be used to infer the qualities of the minds that produced them. They can persist long after the acts were performed, thus providing "frozen" or "fossilized" behavioural data. Some artefacts are sufficient to describe taxa the character- istics of which are otherwise completely unknown. Perhaps most impressive is that building has ramifications throughout the whole complexity of adaptation. Hansell argues convincingly that evolutionary changes in the choice of building materials may effect changes even in social structure; for example, in wasps the change from building with mud to building with vegetation allowed group sizes to increase and so for sociality to emerge.

The book is not without flaws. The author's special field of study is the housebuilding of caddis-fly larvae, and occasionally one feels that the book contains more than one ever wanted to know about these insects. By and large, vertebrates are under-represented compared with spiders and wasps - the use of hammer-stones by Ammophila wasps is mentioned four times, hammer-stone use by sea otters or chimpanzees not at all. The sleeping-nests of great apes rate only two sentences, despite an extensive literature which includes details of such things as the apparent use of dung as insulation against the cold by mountain gorillas!

A recurring problem is how wide to cast one's net, so to speak, in dealing with artefacts. The author is mostly interested in dwellings or other fixed structures, as his title suggests. Yet, at times, and seemingly arbitrarily, he inserts material on tool-use. The use of cafeteria-style trays by Aphaenogaster ants to carry off food is memorable, but why was this included when (for instance) probing with a cactus spine for insect prey by Galapagos finches was omitted? The author might better have left out tool-use altogether, as this has already been definitively dealt with in Benjamin Beck's Animal Tool Behavior, published by Garland in 1980 (for review see Nature 289, 616; 1982). In fact, the two books are largely complementary and show many resemblances in emphasis and viewpoint.

Overall, this is a book of thoughtful analysis, always enlivened with entrancing details of natural history. Everyone knows of the marvellous bower-birds of the Antipodes. But who was aware that one species changes the flowers in its bower daily, or that another spends hours trimming leaves above its arena so that sunlight can penetrate, enabling the bird to show off its plumage?

W.C. McGrew is Senior Lecturer in Psychology at the University of Stirling.

\section{New in paperback}

History of the British Flora: A Factual Basis for Phytogeography, 2nd Edn, by Sir Harry Godwin. Publisher is Cambridge University Press, price is $£ 18, \$ 36$. For review see Nature 261, 527; 1976.

- The Illustrated Natural History of Selborne, an attractively-produced edition of Gilbert White's classic book, compiled by Ronald Davidson-Houston. Publisher is Papermac, price is $\mathbf{£ 8 . 9 5}$. 